\section{Diseño e identidad en las economías regionales. Caso industria textil Mar del Plata, Argentina ${ }^{1}$}

Design and identity on regional economies. Textile industry of Mar del Plata, Argentina

\section{Cómo citar:}

Monacchi, M. 2020. Diseño e identidad en las economías regionales. Caso industria textil Mar del Plata, Argentina. Designia, 8(1), 51-77

${ }^{1}$ El presente trabajo se desprende del proyecto de investigación de la autora en calidad de becaria de la Universidad Nacional de Mar del Plata, Argentina; realizado en el período 2017-2020.

* Diseñadora Industrial de la Universidad Nacional de Mar del Plata (UNMdP), Argentina. Maestranda en la Maestría en Diseño orientada a la Estrategia y Gestión de la Innovación, de la Universidad Nacional del Noroeste de Buenos Aires (UNNOBA), Argentina. Fue becaria de investigación de la UNMdP, primero

como estudianteavanzada y como becaria de posgrado. Sus investigaciones se desarrollan en el campo del diseño y su aporte en laspequeñas y medianas empresas del clúster textil-indumentaria local. Es participante del Grupo en Investigación en Diseño

Sustentable(GIDSu - CIPADI -UNMdP). En ese marco, formó parte de la Certificación en Diseño Sustentable, registrada bajo propiedad intelectual $n^{\circ} 17017885$, herramienta de sustentabilidad para microempresas locales. E-mail: celimonacchi@gmail.com ORCID: https://orcid.org/0000-0002-0755-8694
Palabras clave:

Identidad, diseño, economías

locales, mercados globales,

industria textil argentina.

Key words:

Identity, design, local economies, global markets, Argentinian textile industry.

Recibido: $20 / 03 / 2020$

Aceptado: 08/05/2020 


\section{Resumen:}

Las tensiones suscitadas entre lo local y lo global en la posmodernidad son objeto de estudio para numerosos autores. Sus efectos en la cultura, economía, política y sociedad son evidentes e insoslayables. La identidad, como construcción social, también se ve alterada por estos procesos y adquiere nuevas formas y dinámicas en la praxis. Desde la perspectiva del diseño, la identidad se vuelve un factor esencial para acompañar el desarrollo de las economías regionales dentro de un mercado globalizado.

Este trabajo es parte de un proyecto de investigación como becaria de la Universidad Nacional de Mar del Plata, Argentina, que indaga sobre la vinculación del diseño y las industrias locales. Sin ahondar en las definiciones epistemológicas, en este artículo, se pretende reflexionar respecto a la identidad de una actividad económica con un fuerte arraigo local, tomando como caso de estudio la industria textil de la ciudad. Su objetivo es determinar cómo el diseño puede colaborar en los procesos de interacción entre los entornos productivos locales y los mercados globales. Para ello, este escrito se apoya en los conceptos que plantean David Morley (2001) y Arjun Appadurain (2001) respecto a la territorialización y la heterogeneización cultural emergentes en la posmodernidad.

\section{Abstract:}

Tensions between global and local issues on posmodernity age are subject of study of many authors. Their consequences on culture, economy, politics and society are evident. The identity, as social construction, is also changed by this process and gets new dynamics in the praxis. From design's perspective, the identity becomes an essential aspect to accompany the regional economies development inside global markets.

This article is part of a research project from Universidad Nacional de Mar del Plata, Argentina; that investigates relationships between design and local industries. In this case, it's reflected on local economies' identity, choosing Mar del Plata textile industry as study case. The aim is to determine how design could collaborate on interactions between local and global contexts. To this effect, the article is supported by David Morley (2001) and Arjun Appadurain (2001) theories about territorial and cultural process. 


\section{INTRODUCCIÓN}

El presente trabajo se propone reflexionar sobre el rol y la participación del diseño en la construcción de identidad en las economías regionales, tomando como caso de referencia la industria textil de Mar del Plata, Argentina. La elección de este caso surge de varias cuestiones: en primer lugar, por la importancia que posee el tejido de punto para la ciudad de Mar del Plata. No sólo representa una de las actividades productivas más significativas, en términos de empleabilidad y producción, sino también por el fuerte arraigo simbólico y cultural del sector asociado a la ciudad, con una marcada impronta inmigrante (Favero, 2011; Monacchi, 2017). En segundo lugar, y a los fines de este trabajo de gran importancia, el tejido de punto, o más conocido como pulóver ${ }^{2}$ marplatense, que había logrado posicionarse en el pasado como souvenir turístico (Costa y Rodríguez, 1998); hoy se encuentra en una lenta decadencia. Es falaz pensar que esta cuestión se debe a la pérdida de calidad del producto o al reemplazo del pulóver por otro objeto simbólico. Más bien refiere a un conjunto de cambios en las dinámicas de turismo y de compra, acompañadas de decisiones empresariales cortoplacistas y un contexto político y económico inestable.

${ }^{2}$ La palabra pulóver deviene de pullover o sweater en inglés; en Colombia conocido como suéter o saco. Alude a una prenda tejida, de forma industrial o manual, cuya función primaria es servir de abrigo y se utiliza encima de una prenda de primera piel (polo, camiseta, sudadera, etc). 
Sin desmerecer estos últimos factores, el desarrollo de este artículo se centrará en analizar aquellas cuestiones vinculadas a lo identitario y simbólico. Su objetivo es entender cómo la acción de diseño puede colaborar en el desarrollo de estrategias que apunten a la creación de valor y a la construcción de la identidad. En este abordaje, la concepción de la identidad no se reduce a una cualidad estática y pasiva, sino más bien a una construcción dinámica que puede ir mutando y remodelándose constantemente (Morley, 2001; Appadurain, 2001). Este fenómeno responde a que los grupos sociales a quienes pertenece dicha identidad, van cambiando. Las circunstancias que dan lugar a esta construcción van sucediéndose unas a otras y el escenario donde se desenvuelve es diferente. Por tanto, pensar que la identidad se mantiene inmutable sería caer en su simplificación absoluta. Este escrito, en oposición a la concepción simplista, pretende ahondar en sus cuestiones más complejas, dinámicas y cambiantes. Así como el mundo posmoderno sólo puede entenderse desde la perspectiva del paradigma de la complejidad, tampoco pueden hacerlo sus factores o subsistemas. En este mundo complejo, migrante, en constante movimiento tectónico social, político, económico, cultural, donde las fronteras, las distancias, tiempos y barreras de los Estados-nación se desdibujan, es imposible pensar a la identidad como una cuestión menor.

Cabe preguntarse cómo es que la identidad, en esta dimensión tan compleja que se menciona, puede tener injerencia en un caso tan nimio como puede ser una industria local de escala nacional como la que se intenta analizar. Y particularmente, cómo esta cuestión que apela a lo simbólico y cultural, puede impactar sobre una actividad productiva cuyo eje primordial es lo técnico y económico. David Morley (op.cit) retoma la idea de Foucault cuando define indispensable "desarrollar enfoques que permitan vincular nuestro análisis de "las pequeñas tácticas del hábitat" con las "grandes estrategias de la geopolítica"" (p. 132). Es decir, lejos de desmerecer estas situaciones cotidianas, el autor propone interactuar con ellas y pensar abordajes donde puedan incluirse, porque traccionan y tensionan con el mundo macro. Estos casos demuestran cómo las expresiones de estos grupos más pequeños y poco llamativos también hablan de ellos, de sus modos y dinámicas, de sus resistencias y concesiones para sobrevivir en el sistema.

Por otro lado, este análisis de la identidad no pretende quedar reservado únicamente retomar el pasado. No es necesario enfocarse en una historia introspectiva, sino explorar su sentido extrovertido, donde la identidad se constituye a partir de los vínculos con los demás (Massey en Morley, op.cit). Esta mirada extrovertida exige superar la nostalgia del pasado desde una concepción melancólica, para poder construir prospectivamente a partir de ella. "El potencial de recuperar lo perdido desde un lugar positivo (...) para negociar el futuro" (Allon, F, 2000, p. 284). El objetivo de esta monografía se alinea a esta idea. 
Aproximarse a la cuestión identitaria no puede someterse a los tradicionales recortes tempo-espaciales, como fotografías estáticas. Es necesario el desarrollo de una narrativa que permita profundizar en el camino recorrido y entender las lógicas y sucesos. En el caso de la industria textil marplatense, los inicios de la tradición del tejido de punto en Mar del Plata están fuertemente ligados a las olas inmigratorias europeas de las décadas del ' 40 y ' 50 del siglo XX, producto de las sucesivas Guerras Mundiales (Favero, 2008). Esta condición generó que la incipiente actividad textil en la ciudad, adquiriera una marcada estructura de tipo familiar, donde el oficio se constituía como capital esencial y la transmisión del mismo sólo se producía entre las redes parentales y étnicas más cercanas. En primera instancia, se trataba de una actividad artesanal en su totalidad y de baja escala productiva, pero el impulso de una demanda creciente por parte del turismo y el crecimiento de la ciudad, permitió la formación de un conglomerado de empresas abocadas al ámbito textil. Además, esta expansión provocó la necesidad de ampliar las estructuras productivas y descentralizar los procesos en unidades más pequeñas que trabajaban en paralelo para distintas empresas o fábricas. Esta dinámica de trabajo configuró una modalidad que aún hoy persiste en la industria local: el trabajo a "fasón" ${ }^{3 "}$. La proliferación de pequeños talleres informales que trabajaban para las empresas, contribuyó a la conformación de un cordón productivo vinculado a la actividad que excedía las fronteras de la ciudad y comenzaba a extenderse por otros puntos cercanos.
${ }^{3}$ El trabajo a fasón implica producir para un comitente, que puede ser otra empresa o cliente, que luego venderá ese producto al público bajo su marca propia. Es una instancia de tercerización laboral, en el que una empresa-marca contrata los servicios de otra empresa-fábrica para la realización de un producto semi o totalmente terminado. 
Paulatinamente, este proceso de fabricación, que comenzó siendo de forma manual se fue sistematizando y mecanizando, provocando un cambio del sistema laboral ya que los trabajadores debieron adecuarse a las innovaciones tecnológicas y las nuevas pautas culturales (Favero, 2011, 2012, 2014). Las figuras 1 y 2 evidencian estas estructuras fabriles locales a mediados de siglo XX.
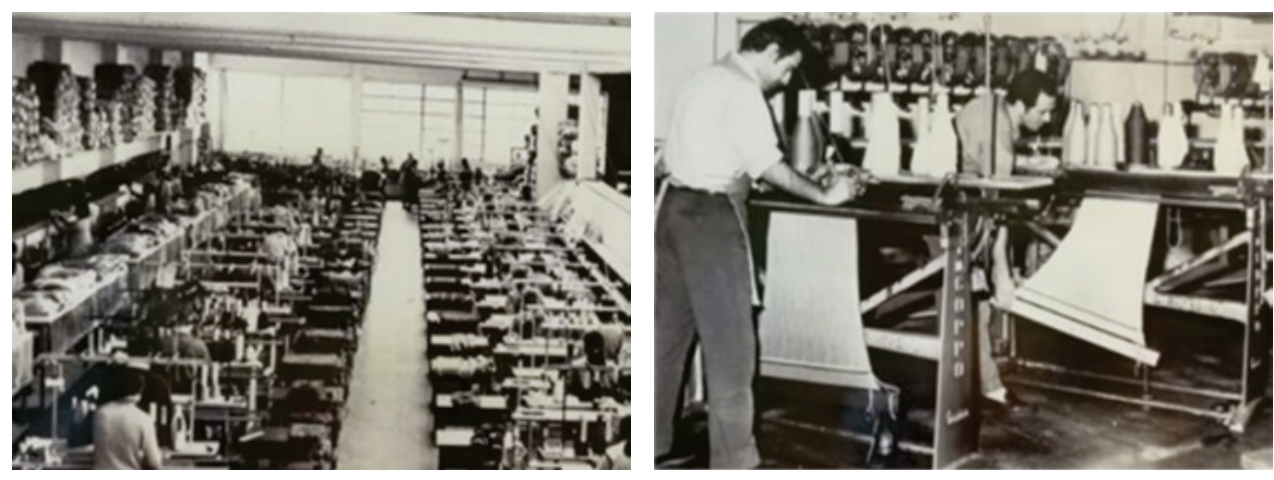

Figura 1 y 2. Fábrica textil de Mar del Plata, Tejidos Raquel, década de 1960. Fuente: Recuperado de: https://www.lacapitalmdp.com/mar-del-plata-lacapital-nacional-del-pulover/. 10 de Junio, 2020.

Con el desarrollo y expansión de la ciudad, y su consolidación como epicentro turístico, la producción textil se complejizó manteniendo algunas estructuras y añadiendo valor agregado a partir de la incorporación de tecnología y programación. La economía de finales de los años ‘70 y la evolución de la microelectrónica, permitieron acercarse a los avances de la tecnología a nivel internacional. De esta forma se incorporaron nuevas maquinarias electrónicas vinculadas al tejido de punto, acompañadas por el salto generacional de padres a hijos con una nueva mentalidad de negocios. Esto permitió un salto cualitativo de la industria, incrementando su capacidad productiva y abriendo nuevos mercados. Además, el pulóver marplatense alcanzó su apogeo convirtiéndose en un significador social: una especie de souvenir turístico obligado de quienes visitaban nuestra ciudad (Costa y Rodríguez, 1998). En consonancia con este fenómeno, Mar del Plata fue nombrada Capital Nacional del Pulóver por el Municipio local y la Subsecretaría de Turismo provincial, convirtiéndose en un slogan de promoción turística. 




Figura 3. Cartel de ingreso a la ciudad de Mar del Plata, Argentina. Fuente: Secretaría de Desarrollo Productivo e Innovación del Municipio de General Pueyrredón. Año 2018.

La apertura tecnológica de las décadas del '70 y ‘80, y la incorporación de la microelectrónica en los ‘90, permitieron el adecuamiento del sector local a los cambios a nivel mundial en materia de innovación. Esto se tradujo en un aumento en la capacidad productiva textil, que no se vio acompañada por un incremento en la demanda del producto. Además, el ingreso de productos importados, cuyos precios 
generaban una competencia desleal con los producidos localmente, ocasionaron un estancamiento del sector textil marplatense (Gennero de Rearte, 1993). La economía globalizada de los '90 y la apertura de las importaciones produjeron una estrepitosa caída del sector, por la incapacidad de competir con los productos extranjeros. La búsqueda de nuevos mercados y estrategias de comercialización por parte de los empresarios locales, basados en la venta mediante viajantes y la apertura de outlets y franquicias, generó el agotamiento del carácter identitario del pulóver local. Sumado a esto, las modificaciones en las pautas culturales de consumo y turismo también fueron factores que provocaron la disminución de las ventas y la producción local.

Para entender el panorama actual de la industria textil es necesario hacer una mirada no sólo en lo local, sino también en el marco nacional. En Argentina, tras una fuerte reactivación durante 2013, el sector representaba el $7 \%$ del valor agregado industrial para el 2015, incluyendo cerca de 20.000 empresas y 450.000 puestos de trabajo directos (Boletín de Fundación Pro Tejer, 2017). Estos datos demuestran la importancia de la cadena textil-indumentaria en la economía nacional, asociada directamente a la fuerte presencia de pequeñas y medianas empresas (PyMEs), su vinculación estratégica con el desarrollo de economías regionales, su orientación al mercado interno y su potencialidad en mercado externos de lujo (Monacchi y Canetti, 2018).

Respecto a la región del Partido de General Pueyrredón, Mar del Plata y zona, hacia el año 2004, el sector se componía por firmas abocadas al tejido de punto, a la confección de indumentaria y la provisión de servicios afines (tintorerías, estamperías, talleres, etc.), representando el 10\% del valor agregado industrial de la región (Mauro y otros, 2012). La industria textil y confeccionista marplatense presenta características propias de los distritos industriales: presencia mayoritaria de pequeñas y medianas empresas con marca propia, elevada interacción con talleres subcontratistas locales, flexibilidad productiva, elevado enraizamiento en el territorio, una importante circulación de conocimiento no codificado entre actores y una presencia creciente de profesionales de diseño (Gennero de Rearte, 2008). A su vez, marcas a nivel nacional 
e internacional, recurren a las fábricas locales para la producción de sus diseños; la mayoría de las empresas de tejido de punto funciona bajo esta modalidad de subcontratación o putting-out debido al reconocimiento de su calidad, tanto en la confección como en la materia prima (Monacchi, 2015). Actualmente, se registra una baja del nivel de actividad de la cadena a nivel nacional, llegando a -24,7\% en Abril de 2017 (respecto de Abril de 2016), y acumulando entre enero-abril de 2018 un -6,5\%. Esta caída se contrapone al aumento de las importaciones referidas al rubro, que llegaron a un $21 \%$ más en toneladas y un $39 \%$ en dólares durante el mes de abril de 2018 en la comparación interanual (Boletín Económico Abril 2018, Fundación Protejer).

En este contexto desfavorable, se suman algunas problemáticas locales. Desde el punto de vista económico, las fábricas que trabajan a fasón dependen enteramente de sus comitentes y tienen reducidas posibilidades de negociación, ya que éstas absorben el 70\% de la producción y fijan los precios del servicio (Canetti y otros, 2014). A nivel social, las empresas desintegran su actividad (es decir, se recurre a la terciarización de la producción), liberándose de los costos fijos que implican trabajadores y maquinarias. En la localidad, este paradigma invisibiliza nodos productivos importantes y multiplican los problemas de los talleres textiles y de confección: las relaciones de empleo son asimétricas, existen bajos niveles de conexión entre nodos productivos, el flujo de trabajo es irregular, y no existe un estímulo a la estabilidad laboral (Ruppel, 2017). Otra problemática que se detecta en el conglomerado local es la desigual relación que se genera entre las fábricas locales, que trabajan como fasón para las marcas nacionales. El poder de negociación de las empresas textiles respecto a su producto queda subsumido ante la cantidad de intermediarios que participan en la cadena y los tiempos y precios exigidos por las marcas. De esta forma, el fabricante debe adecuarse a los requerimientos de las marcas en pos de no perder al cliente, cuyos volúmenes de producción son los que permiten la estabilidad productiva en las empresas durante todo el año. El carácter fasón de las empresas locales provoca que la venta al público de producto propio en Mar del Plata, resulte una actividad relativamente secundaria, para complementar la fluctuancia productiva o como forma de disminuir stocks o prendas defectuosas. 


\section{Entendiendo identidades: Industria textil marplatense}

Este recorrido por los inicios de la industria textil marplatense nos permite generar algunas afirmaciones y otras líneas de análisis respecto a la cuestión identitaria. Para ello, se propone tres dimensiones dentro de este marco, que si bien están relacionadas unas con otras, servirán a los fines de facilitar una mejor comprensión: el tejido de punto como oficio, tejido de punto como producto, tejido de punto como actividad económica. La concepción del tejido de punto como oficio, se centra en el valor del intangible y las lógicas que devienen de este know how específico que aún hoy se evidencian. El tejido de punto como producto se enfoca en el carácter simbólico del objeto material y en el análisis del tejido de punto como actividad económica, enfatiza en las dinámicas productivas en entornos locales, nacionales y globales.

\section{TEJIDO DE PUNTO MAR DEL PLATA}

Figura 4: Tres dimensiones dentro de la identidad del tejido de punto en Mar del Plata. 


\section{El tejido de punto como oficio}

En primer lugar, podemos configurar una industria textil fuertemente arraigada a la ciudad de Mar del Plata por varias cuestiones. El fenómeno de la inmigración, principalmente italiana y española, signó la expansión y crecimiento de la ciudad, y promovió el desarrollo de nuevas actividades económicas, tales como la pesca, la construcción y la producción textil. En este contexto, el factor oficio o técnica, se constituyó como un intangible de gran valor recelosamente transmitido a través de las generaciones y las redes étnicas. El desarrollo de Mar del Plata como epicentro turístico resultó otro puntapié para el crecimiento de la industria textil, en términos de adquisición de maquinaria, capacidad productiva, empleabilidad local, niveles de consumo y compra. Esto dio lugar a la formación de un conglomerado de empresas, fábricas, proveedores y talleres vinculados a la actividad textil. Este conocimiento específico ya no era reservado únicamente a las familias empresarias por la expansión y tecnificación de la actividad, pero sí permanecía dentro del clúster, afincado a la ciudad y sus alrededores.

Debemos aclarar que el oficio del tejido de punto en Mar del Plata tenía una particularidad que aún hoy se evidencia en la industria: el carácter sumamente artesanal ${ }^{4}$. Es posible que esta cuestión pueda estar vinculada al legado inmigrante, principalmente italiano, y a las dinámicas productivas que se daban (y continúan dándose) en el país de origen. La concepción italiana del valor del oficio y la técnica en la producción, aún se puede apreciar en el design italiano. Se podría referir a las industrias como una suerte de slow factories; donde si bien los productos son fabricados en serie, muchos detalles son artesanales y demandan tiempos excesivos para cualquier otro tipo de producción masiva. Estas características aún se visualizan en muchas empresas de diseño italianas, de gran trayectoria y envergadura. En esta lógica prima la calidad por sobre la cantidad, el detallismo y las terminaciones, la viabilidad de producir tiradas más cortas y diversas, la precisión de la técnica para lograr que los toques artesanales puedan reproducirse en serie. Podemos trazar un paralelismo con el tejido de punto marplatense, no sólo por la raíz común, sino también por esta dinámica productiva semi-artesanal. Por ejemplo, a

${ }^{4}$ El término artesanal es utilizado, a los fines de este trabajo, para enfatizar la cuestión manual que se manifiesta en la industria local. Si bien la actividad textil es sistematizada y tecnificada, la artesanalidad en este caso reside en la gran cantidad de operaciones manuales, con detalle y precisas que se realizan "uno a uno" en la relación producto-operario. Además, la dinámica local de fábrica boutique, donde las tiradas de producción son cortas y variadas, provocan dificultad para automatizar las tareas por parte de los operarios, quienes deben ejecutar acciones distintas con cada modelo nuevo. A los fines de eficiencia productiva, estas fábricas que requieren de versatilidad en sus estructuras resultan complejas, desorganizadas y poco eficientes respecto a aquellas que poseen sus líneas de producción definidas y constantes. 
El remallado es una técnica de confección que utiliza la máquina remalladora. Ésta consta de una base circular con puntines (agujas) que calzan en cada uno de los puntos del tejido, y una aguja superior que va cosiendo cuando se acciona el pedal. Genera una costura en forma de cadena, permitiendo el estiramiento del tejido pero no su deformación. La numeración de las remalladoras depende de la distancia entre los puntines y el grosor de los mismos, coincidentemente con la galga (podríamos traducirlo en densidad) del tejido.

62

diferencia de otras ciudades del país, también productoras de tejido de punto, en el caso marplatense, la gran mayoría de la confección se realiza con remalladora ${ }^{5}$. Como se muestra en las figuras 5 y 6 , esta máquina de estructura circular produce una costura prolija, que acompaña las cualidades del tejido de punto, permite su estiramiento y mejora la caída sin deformarse.
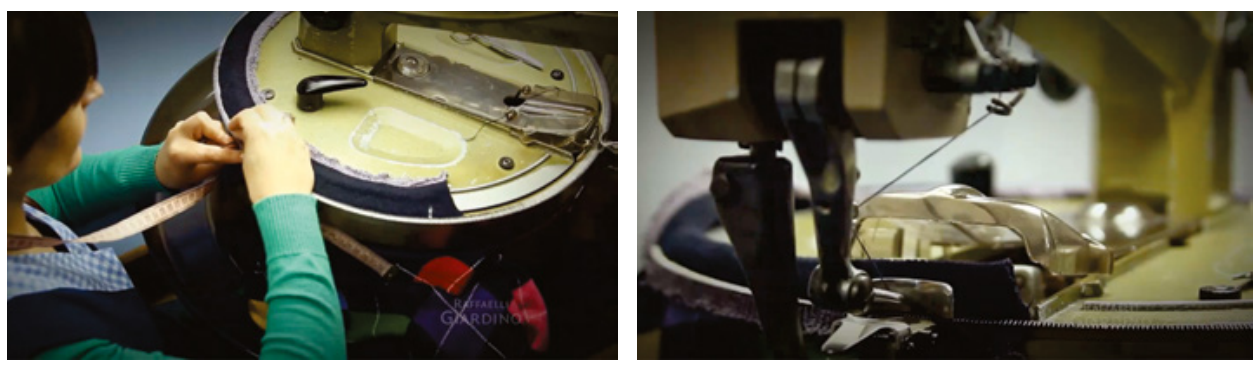

Figura 5 y 6: El uso intensivo de la máquina remalladora como símbolo del oficio local. Extraído de página web institucional de la empresa Raffaelli Giardino, Mar del Plata, Argentina.

.Fuente: Extraído de video en línea: https://raffaelligiardino.com.ar

Sin embargo, representa un método de confección sumamente manual, lento y que requiere de personal calificado para lograr la precisión óptima. Otras instancias productivas, tales como las terminaciones ${ }^{6}$, también se realizan a mano, sin la intervención de ninguna máquina y no constituyen un proceso sistematizado, sino que varían dependiendo del modelo en producción.

${ }^{6}$ Las terminaciones, como su nombre lo indica, son costuras manuales para esconder "colitas, hilachas, hilos, atraques, nudos" resultantes de los procesos anteriores. El tipo de terminación depende específicamente del modelo que se esté confeccionando, y es el último proceso antes del lavado y finalización de la prenda.

Desde los inicios de la actividad en la ciudad, la confección se realizó con estos parámetros y aún perviven en la industria, aunque enfrentan serios problemas en relación a la mano de obra y la antigüedad de la maquinaria. Estos métodos productivos, aunque su aporte parezca invisible, forman parte del concepto de calidad que siempre ha caracterizado al pulóver local, y por el cual clientes y marcas han optado por Mar del Plata para comprar y producir. Las empresas locales han comprendido la importancia de mantener estos estándares como diferencial de producto y han luchado para mantener, transmitir y mejorar la técnica y la mano de obra calificada. "Sin capacitación no hay industria" reza el slogan de la Escuela de Capacitación Textil dependiente de la Cámara Textil, donde se han dictado cursos de oficios antes mencionados. 
En paralelo a estas cuestiones, es necesario resaltar que el clúster local cuenta además con tecnología de avanzada para satisfacer las necesidades de sus clientes. El empresariado local siempre se ha caracterizado por la inversión en maquinaria para lograr mayor complejidad en los diseños, y acompañado de capacitación en recursos humanos para la implementación de estos avances. Esta extraña vinculación que comulga entre la artesanalidad de la técnica legada y la tecnología de punta de las empresas marplatenses, puede asociarse a lo que Joao Costa (1994) define como el fenómeno de la acumulación en el mundo posmoderno, la coexistencia de lo nuevo y lo viejo. El autor explica que este sustrato material y simbólico no termina de despegarse y en él subyace un sentimiento de nostalgia de aferrarse y hacer subsistir al pasado. Justamente, este convivir entre la tecnología de punta y las técnicas antiguas, constituyen la calidad del tejido local y forma parte de su identidad, por ello los empresarios se esfuerzan en mantener ambas cuestiones.

Por otro lado, también en relación a la técnica, es importante resaltar el rol que cumple el clúster local como empresas-fasón. Gran cantidad de marcas nacionales producen sus tejidos de punto en Mar del Plata pero, en muchos casos, sus departamentos de diseño no poseen el conocimiento técnico de la producción textil que sí posee el clúster. Las propuestas de diseño se hacen a través de una fotografía, un dibujo o un modelo físico, y son las fábricas locales las encargadas de decodificar y verificar la factibilidad de lo que se quiere hacer. Esto denota la concentración del conocimiento técnico en el territorio y la tecnología de punta. También, al estar presente la cadena de valor en su totalidad en Mar del Plata, la posibilidad de abarcar variados procesos que exceden al tejido propiamente (estampados, bordados, teñidos, etcétera). Este know how propio y construido a través de la trayectoria y experiencia, forma parte de la identidad del tejido local, y es el que hace que las marcas nacionales sigan confiando su producción y diseños en Mar del Plata. En este sentido, se retoma la idea de Diana Crane (Crane en Appadurain, 2001) respecto a las hermandades o universidades invisibles. La autora define estos territorios intangibles en los cuales circula conocimiento, afinidades, pertenencia, símbolos en común y relevancia mutua. Estos espacios articulados entre varios actores con sentimientos y entidades en común son aquellos que refuerzan la idea de identidad asociada al territorio. En este caso, la industria textil local, podría funcionar como una de ellas. 


\section{El tejido de punto como producto}

Podemos afirmar que el pulóver marplatense se convirtió durante una época, en un elemento con un fuerte componente simbólico asociado a la ciudad, que aún pervive en el imaginario colectivo. Siguiendo el análisis de Costa, E. y Rodríguez, G. (1998), es pertinente enfocar el producto pulóver desde dos perspectivas distintas: por un lado, como producto físico, y por otro, desde su aspecto simbólico, cuyo aporte resulta más interesante a los efectos de este trabajo.

Como producto físico, surgió durante la Primera Guerra Mundial como prenda de abrigo tejido por las mujeres para los soldados que se enlistaban, y paulatinamente fue ingresando en el sistema de la moda mundial, de forma más industrializada. En Argentina, su uso se masificó en la década del '30 con la gran recesión mundial, y la oferta del recurso lanero en cercanía fue un factor para la implementación de esta prenda netamente artesanal. Como se mencionó anteriormente, la industrialización y masificación del pulóver como prenda, fueron consecuencia del arribo al país de una gran cantidad de inmigrantes, principalmente italianos.

7 Indumentaria urbana y en algunos casos deportiva. En Colombia se conoce como chaqueta.

\section{${ }^{8}$ Esta reconversión del} sweater en un estilo más urbano va de la mano de la utilización de recursos en la confección, como la tapacostura, el uso de hilados blends o sintéticos, como el elastano, poliamida o viscosa, tipologías más asociadas a cortes de indumentaria, entre otras cuestiones. Esta situación es posibilitada por el avance tecnológico en cuanto a maquinaria e hilados.
Según estos autores, el pulóver a través de los años se encargó de cubrir tres aspectos simbólicos y fisiológicos esenciales: como abrigo y reparo de las inclemencias climáticas, como prenda de vestir vinculada al mundo de la moda, y como souvenir turístico, cuya interpretación en la ciudad de Mar del Plata se dio de forma especial (Costa y Rodríguez, op.cit). El agotamiento de estos tres recursos provocó lentamente una decadencia de este producto en el mercado. La sustitución del tejido de punto por otras tipologías tales como las camperas y buzos ${ }^{7}$, más livianas y accesibles, y el calentamiento de los distintos ambientes, compitieron con el pulóver como forma de abrigo. En el contexto marplatense esta intromisión en el mercado, se vio evidenciada en la avenida Av. Juan B. Justo, tradicionalmente caracterizada por la fabricación y venta de tejido de punto, donde a partir de mediados de los años ' 80 y principio de los '90, comenzaron a asentarse comercios dedicados a la venta y confección de camperas (Gennero de Rearte, op.cit). En segundo término, el pulóver como prenda de moda y vinculada a las pasarelas europeas tuvo su auge entre 1960 y 1985, donde el tejido de punto se consolidó como símbolo de elegancia, pero a partir de la tendencia del vestir informal y urbano y la expansión de las telas sintéticas, sufrió una recaída. Respecto a esta cuestión, en la actualidad, podemos decir el sweater se ha reinventado de forma que ha dejado de ser una prenda formal y de lujo para adaptarse al estilo urbano y casual ${ }^{8}$. 
Por último, la concepción del pulóver marplatense como souvenir turístico surgió con el establecimiento de Mar del Plata como punto estratégico del turismo de masas, a partir de mediados de la década del '50 y decayó notablemente durante la década del ' 90 . Este fenómeno de regalar pulóveres marplatenses de regreso de las vacaciones, se vinculaba a la concepción artesanal de éste, sus diseños novedosos y un packaging con una clara identificación de la ciudad, con slogans tales como "Mar del Plata, capital del verano" o "Mar del Plata, ciudad feliz". En este marco, tampoco resulta menor la nominación de la ciudad como "Capital Nacional del Pulóver", por el Gobierno Municipal y la Cámara Textil, donde claramente quedaba inmortalizado el pulóver como producto simbólico. Este impulsor de valor ${ }^{9}$ de la industria a partir de su fuerte carga significativa no fue intencionado por parte de los empresarios, sino que surgió de forma espontánea y fue aprovechado posteriormente cuando se advirtió este fenómeno (Abad et. al, 1999).

En este sentido, los industriales marplatenses no lograron canalizar efectivamente este recurso y provocaron la "muerte del souvenir turístico" (Costa y Rodríguez, op.cit). La búsqueda de beneficios a corto plazo, a través de la incorporación de tecnología y la fabricación de producción excedente, condujeron a la necesidad de ubicar los productos a través de nuevos puntos y formas de comercialización. Los viajantes, la apertura de franquicias en todo el país y la masificación de la segunda selección, provocaron que este carácter identitario del pulóver marplatense se fuera diluyendo. La modificación en los patrones de conducta vinculados al turismo también fueron detonantes de este agotamiento del valor impulsor que había surgido de forma espontánea y casual, una vez descubierto, no pudo ser sostenible en el tiempo. La rápida accesibilidad y cercanía geográfica ${ }^{10}$, convirtió a Mar del Plata en el balneario de Buenos Aires, capital argentina, ya no como punto de veraneo quincenal o mensual, sino más bien como un lugar habitual de fin de semana. Dada la brevedad e informalidad de la visita a la ciudad, los turistas que frecuentan Mar del Plata actualmente prefieren invertir tiempo y dinero en entretenimiento, descanso y ocio, y no en paseos de compras (Abad et.al, op.cit). Esta caracterización del turista marplatense responde a un aspecto sociológico vinculado a la falta de tiempo ocioso, la necesidad de que todo suceda prematuramente y de forma veloz; y al individualismo, que ha provocado que se vaya perdiendo cada vez más la costumbre de regalar y más aún de regreso de vacaciones (Costa y Rodríguez, op.cit). Otro factor
${ }^{9}$ Se entiende por impulsor de valor a un elemento que pueda permitir una ventaja competitiva sostenible en el tiempo en una economía determinada. El conocimiento de este elemento, su mantención y ampliación por parte de los empresarios es necesario para que siga otorgando beneficios a la empresa (Abad et. al, 1999), pero la capacidad de reversionarlo y renovarlo a partir de los movimientos que se registran en el mercado y las nuevas tendencias, es esencial para la sostenibilidad en el tiempo del impulsor de valor.

${ }^{10}$ Mar del Plata es una ciudad balnearia que queda a $400 \mathrm{~km}$ aproximadamente de Buenos Aires, la capital argentina. La construcción de carreteras y autopistas agiliza el viaje entre estas dos ciudades y hace que los turistas visiten la ciudad los fines de semana. 
a tener en cuenta, es que Mar del Plata ya no posee el monopolio balneario que solía tener décadas atrás. Actualmente, numerosas ciudades balnearias cercanas poseen infraestructura y paisajes similares donde la gente puede elegir vacacionar. Y más aún se amplía el abanico de opciones, si analizamos la posibilidad de viajar al exterior o a otras ciudades del interior del país gracias al desarrollo de las rutas terrestres, marítimas y principalmente aéreas. Estas cuestiones hacen que Mar del Plata ya no tenga la exclusividad turística que solía tener durante la época estival.

Ante esta "muerte del souvenir turístico" y el decaimiento de la industria textil en general, podemos afirmar que se percibe en las empresas cierta nostalgia del pasado de esplendor que caracterizó a la ciudad y su producto estrella. A diferencia de lo que describe Appadurain (op.cit) respecto a la memoria sin nostalgia que caracteriza al capitalismo tardío y que muchas veces genera melange en los productos, carentes de identidad propia; en el caso local sucede al revés. Aferrarse a la identidad (en términos de estética, de marca, de dinámicas productivas) que en su momento resultó exitosa y que en la actualidad, ha perdido vigencia, es una reacción recurrente en el conglomerado local. Esta nostalgia ha generado que muchas empresas, en su oferta al público, se hayan quedado estancadas en tendencias viejas, tipologías que hoy resultan retro, colores y gráficas poco novedosas.

Esta situación deja expuesta el desfasaje que se evidencia entre la oferta propia de la empresa y lo que ésta produce como fasón para otras marcas nacionales (Monacchi, 2020). En esta última dinámica, la empresa cumple su rol de fábrica. Desde la visión del tejido de punto como producto, las empresas textiles locales reciben la información y los diseños por parte de las marcas nacionales, y lo traducen a sus posibilidades productivas. Estos diseños son el resultado de búsquedas y selección de tendencias (tipologías, colores, hilados y terminaciones) que las marcas hacen durante la etapa de colección y que en general, responden a las conductas de moda de las pasarelas internacionales. Se podría afirmar entonces, que las empresas locales son receptoras de información procesada de tendencias internacionales, materializada en propuestas de diseño. Sin embargo, en el afán de continuar fieles a su producto "pulóver marplatense", pocas empresas hacen uso de esta información y lo aplican a sus propias colecciones. Éstas, suelen reducirse a tipologías básicas, de fácil tejido y confección, a programas desarrollados anteriormente y muchas veces sin la previsión o planificación propia de una colección. Estas situaciones generan que el producto que la empresa local ofrece al público esté en desventaja en 
comparación con lo que la empresa es capaz de producir y de hecho, hace para otras marcas. Este desfasaje podría darse por varios factores: en primer lugar, desinterés por la marca propia o puesta de mayor atención en el trabajo a fasón, que mantiene la estabilidad productiva y laboral. En segundo lugar, escasez de profesionales de diseño en las empresas. En varias fábricas locales, el diseño del producto está en manos de los propios dueños, que no sólo se encargan de eso, sino que también se ocupan de tareas administrativas y operativas, lo cual dificulta darle importancia a la cuestión de diseño. En tercer lugar, la problemática también está en el anclaje en una identidad estética pasada, que ya resulta obsoleta. Pocas empresas son las que han logrado continuar construyendo sobre esta identidad, sin perder su impronta, pero acompañando el producto con diseño, marketing, estrategias de comercialización, etc. Otro punto que resulta interesante resaltar es que, de la misma forma que no hay estrategias de diseño concisas de producto en las empresas locales, tampoco lo hay en la identidad marcaria de las mismas. Pocas empresas han desarrollado y gestionado una imagen de marca que exprese su identidad y que la transmita al consumidor, a través del branding, del marketing y de la experiencia de usuario (Monacchi, op.cit). 


\section{Tejido de punto como actividad económica}

La condición de las empresas marplatenses como fasones es una cualidad que ha marcado la actividad desde sus inicios. En este marco, podemos decir que cerca del $60 \%$ de la producción de tejido de punto de las empresas nacionales se produce en Mar del Plata ${ }^{11}$. Esto da cuenta de la importancia del clúster en términos de conocimiento, capacidad productiva, know how, calidad de producto. Sin embargo, con la apertura de las importaciones de los últimos años, el tejido de punto producido del exterior (de países orientales principalmente) ha resultado una competencia muy desleal con la industria local. Muchas marcas nacionales comenzaron a producir allí sus sweaters, a precios mucho más bajos, pero con algunos limitantes, como la cantidad de prendas por modelo y color o la calidad de la confección. Esto provocó que los fabricantes locales, para no perder a sus clientes-marcas, comenzaran a volcarse a la dinámica de fábrica boutique: dada la flexibilidad de sus fábricas, podían permitirse tiradas productivas más cortas, modelos exclusivos o con

\author{
${ }^{11}$ Según datos otorgados \\ por Juan Pablo Maisonnave, \\ Presidente de la Cámara Textil \\ de Mar del Plata, 2018. \\ ${ }^{12}$ Para precisar este concepto \\ de "limitado", nos referimos \\ a que no se explotan todas \\ las potencialidades que \\ actualmente ofrecen las redes \\ sociales. En referencia a esto \\ podemos detectar: intermi- \\ redes sociales, no hay una \\ uniformidad en la imagen \\ de marca que se presenta, \\ no se realiza venta online \\ a través de Marketplace u \\ otros formatos, no hay una \\ regularidad en tiempos de \\ respuesta, etc. Si bien esto no \\ sucede en todas las empresas, \\ sí en muchas de las que \\ conforman el conglomerado \\ local
} detalles artesanales, en cantidades reducidas y ofreciendo variedad de hilados. En términos productivos, este tipo de estructura no permite una rígida estandarización de las tareas, ni tampoco la sistematización de procesos para los operarios, sino que exige altos niveles de versatilidad para poder amoldarse a los distintos requerimientos. Sin embargo, en el caso de la industria local, esta modalidad les ha permitido subsistir ante la invasión importadora y continuar con el estándar de calidad que ha caracterizado siempre a esta actividad. De esta forma, algunos clientes-marcas producen en Mar del Plata sus líneas más exclusivas (que siempre son menores en cantidad, pero más costosas) y en el exterior, los modelos básicos de tiradas continuas. Aún así, para la industria local este sistema implica fluctuación productiva, inestabilidad y capacidad ociosa en sus estructuras, aunque les permite trabajar para varias marcas en paralelo (Monacchi, op.cit.).

Por otro lado, las importaciones han ingresado al sistema de producción y consumo nacional en el marco de una sociedad posmoderna y globalizada, donde las telecomunicaciones permiten estas modalidades transnacionales. De la misma forma podríamos considerar la potencial inserción del producto local en otros mercados que excedan las fronteras nacionales; situación que se da en muy pocos casos (Rech, 2019). Es difícil precisar si este fenómeno responde a restricciones impositivas, incapacidad de alcanzar volúmenes productivos, dificultad para cumplir con requisitos exportadores, etc. Sin embargo, lo que sí se detecta es un escaso uso de los medios de comunicación para ofrecer sus productos, tanto en el mercado nacional como en el potencial internacional. Aunque actualmente la gran mayoría de las empresas textiles locales aparecen en Internet (principalmente en redes sociales, aunque con un manejo bastante limitado ${ }^{12}$ ), son muy pocas las que 
venden por medios virtuales y menos aún las que comercializan al exterior. La venta mayorista en el territorio nacional se realiza en la gran mayoría de los casos a través de la dinámica de viajantes; representantes de la empresa que manejan una cartera de cliente y ofrecen las colecciones diseñadas por la empresa o las posibilidades de fabricación para los comercios minoristas.

Estas tensiones entre la producción local y global son las que tanto Appadurain como Morley han ido teorizando. Si bien dichos enfoques están abocados a la cuestión de la movilidad y los medios de comunicación, ciertos conceptos son interesantes de aplicar a la realidad descripta. Por un lado, Morley refiere a un concepto expuesto por Doreen Massey (Massey en Morley, op.cit, p.139) como la geometría del poder. Bajo este enfoque, se define que el poder queda en manos de quién tiene el control sobre su movilidad, estableciendo así una división entre móviles y sedentarios. Mientras que los primeros, gozan del poder de la movilidad y su control sobre ella, el segundo grupo queda reducido a una actitud pasiva y estática. Haciendo el paralelo con la realidad textil local, queda clara la condición de la industria local en este estado sedentario, donde la estrategia resulta meramente defensiva respecto a la movilidad y el control del resto, en este caso la producción extranjera. Si bien el resguardo de la industria nacional es una decisión política, la conciencia del mundo globalizado se consolida más allá de la decisión estatal. Irremediablemente, el tránsito de objetos, personas, tendencias e información se materializa y circula por diversos puntos del globo. Como expresa Morley, este fenómeno globalizador que se constituye arrollador, no debe agarrarnos desprevenidos como cosmopolitas involuntarios (Morley, op.cit), sino más bien utilizando estratégicamente sus recursos en pos de obtener beneficios y oportunidades de ellos. Estas tensiones global-local ponen de manifiesto la necesidad de reforzar la identidad de la industria local, 
redefinir el valor del negocio y las potencialidades de su expansión con miras de mercados más amplios, quizá más exclusivos, o más valorativos de la calidad y la artesanalidad. Es evidente que en el mundo posmoderno, las telecomunicaciones no pueden estar exentas de este plan. Asimismo, Appadurain expresa que la "nueva economía cultural global ya no entra en el binomio de centro-periferia" (2001, p.31) y que existe espacio para nuevos actores o dinámicas de consumo en este orden yuxtapuesto y dislocado. Es posible que en este contexto, la producción local a baja escala, con posibilidad de detalles y precisiones de oficio tengan un lugar mucho más valorado en la escala internacional como objeto de lujo, que en la escala nacional como objeto de una relación a fasón.

Otra cuestión importante a resaltar, es la cualidad del conglomerado textil marplatense con una fuerte impronta $P y M E^{13}$ y familiar. Estas características configuran un perfil empresarial particular, con bajos niveles de profesionalización en puestos estratégicos, donde actualmente transitan un proceso de transición generacional, decisiones de tipo verticalistas que quedan centralizadas en el dueño y el otorgamiento de puestos dentro de la esfera familiar. Estas características conllevan a una impronta muy definida en términos de identidad: la toma de decisiones, dinámicas

${ }^{13}$ La sigla PyME refiere a

las "pequeñas y medianas empresas" en Argentina. La definición nacional establece que se consideran pequeñas empresas aquellas que emplean entre 15 y 60 personas; y mediana empresa de 61 a 235 (Clasificación C-PyME, 2018) productivas, concentración del poder en la figura del dueño/fundador. No se puede definir que esta cuestión sea positiva o negativa para la empresa, pero claramente sí enmarca a una característica identitaria muy fuerte en la industria local. Es posible que muchas de las cuestiones que referíamos anteriormente respecto a la escasa definición estratégica en términos de marketing, imagen de marca, comercio online, entre otros; pueda tener que ver con una visión más técnica, como reflejo de las decisiones de los dueños quienes pertenecen a otra generación. Sin embargo, la entidad familiar, y principalmente en las PyMEs, representa un entorno donde los empleados se sienten parte de la evolución del negocio, cercanos a la figura del dueño, y eso mejora la fidelidad con la empresa. 


\section{El diseño y la "reconstrucción" de la identidad}

En el comienzo de este trabajo se planteó el objetivo de definir cómo la acción del diseño podría colaborar a la identidad en la industria local. Luego de analizar las diferentes dimensiones que se identificaban en el marco de la actividad textil y cómo éstas respondían a cuestiones históricas, culturales, sociales, económicas y políticas, es posible esbozar algunas estrategias que apunten a la "reconstrucción" de esta identidad, desde la perspectiva del diseño.

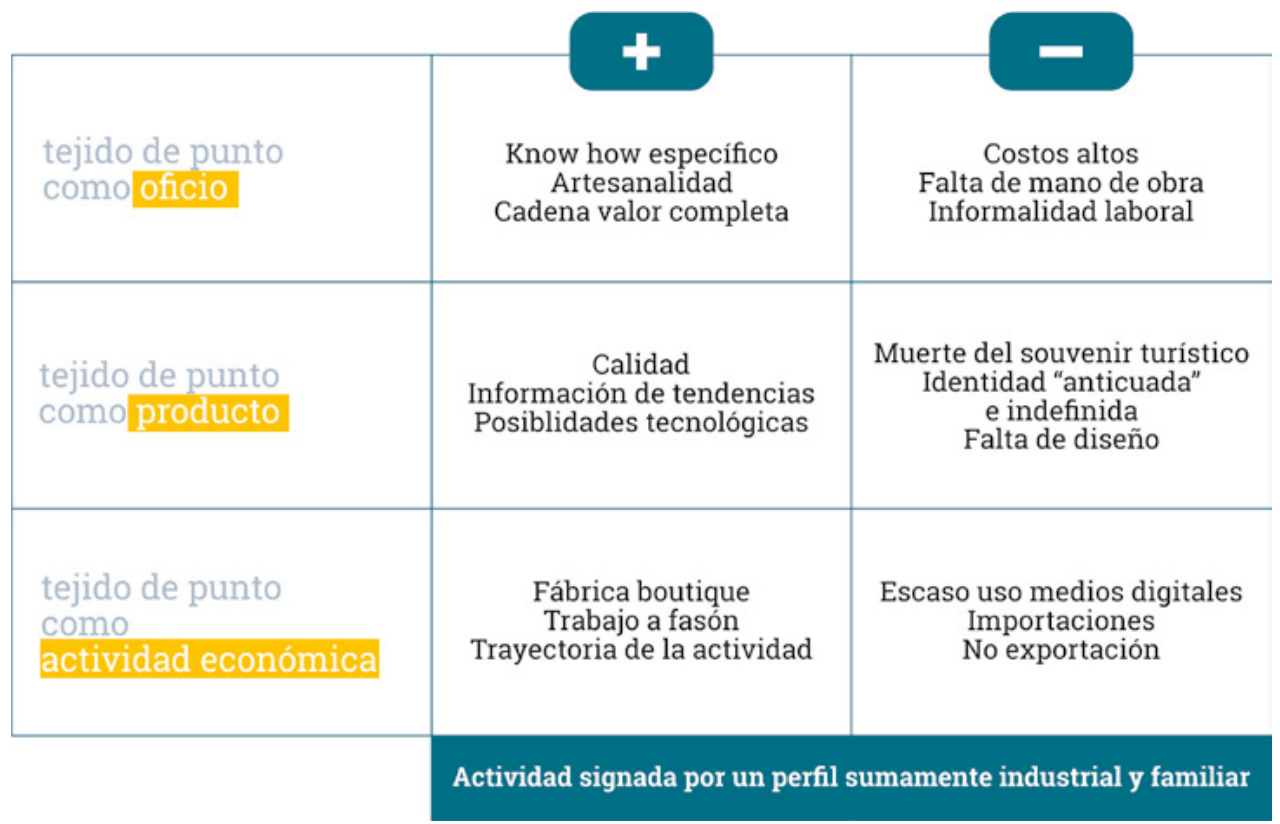

Figura 7. Comparación entre las tres dimensiones del tejido de punto en la industria textil local.

Fuente: autora.

La Figura 7 sintetiza las cuestiones desarrolladas en los apartados anteriores, diferenciando aquellas positivas de las negativas para el sector. Como conclusión parcial, podemos decir que la actividad textil local está signada por un perfil sumamente industrial y familiar, donde el enfoque está puesto en lo técnico en detrimento de otros factores más estratégicos como pueden ser la comercialización, la imagen de marca, el marketing, el diseño. Este perfil define que las acciones dentro del conglomerado estén apuntadas a la primera dimensión, el tejido de punto como oficio, priorizando 
la entidad fabril por sobre la empresarial. Claramente esto provoca que se invierta en tecnología, capacitación técnica y operarios, más que en puestos estratégicos. Esto también explicaría el porqué de la pérdida del impulsor del valor, más allá de la propia coyuntura y la evolución en las dinámicas sociales, la incapacidad de gestión de ese valor espontáneamente logrado y el viraje hacia un modelo enfocado en la producción a fasón más que en el crecimiento de la marca propia.

¿Cómo podría aportar en este marco el diseño? Más allá de la presencia o no de un profesional del diseño dentro de la empresa (aunque éste sería importante, teniendo en cuenta que en la ciudad existe una carrera específica de Diseño Industrial con orientación textil), el rol del diseño siempre ha cumplido un enfoque estratégico, que media entre lo productivo, lo técnico, las tendencias, la disponibilidad de recursos. El diseño posee la sensibilidad para reconocer el valor intangible de la empresa y generar una estrategia donde, dentro de los parámetros posibles y accesibles, ese valor sea gestionado y sostenido en el tiempo. En el caso de la industria local, resulta prioritario desde el diseño, repensar la identidad empresarial, desde todas las ópticas: lo organizacional, estético, gráfico, productivo. Como expresa Paula Miguel (2005), “...la producción económica lleva cada vez más estampado el sello de lo simbólico en la construcción de su valor (...). La oferta y demanda están cada vez más impregnados de contenidos simbólicos, cognitivos y expresivos, ya sea en tanto insumo de la producción o como componente clave en su circulación..." (p.35-36). Esto indica la importancia de reforzar los aspectos simbólicos que hacen a la identidad productiva y principalmente en la pequeña y mediana escala, donde son admisibles nuevas dinámicas creativas y justamente en ellas, puede darse el lugar para la innovación. “El diseño es convocado por su capacidad de crear valor, poder simbólico acreditable en la economía, en relación con las pequeñas unidades productivas enfrentando las brechas que las separan de la gran escala" (Galán, 2011, p.88). 
En esta aldea global (McLuhan en Appadurain, op.cit), el diseño se manifiesta como una forma de promover lo diferente. Lejos de aislarse del entorno global, buscar soluciones que sean válidas en la localidad, en torno a la convivencia de actores, procesos, propuestas. Pero también es importante que puedan trascender hacia nuevos contextos globales haciendo hincapié en el sentido del producto local. Hoy en día, la producción a nivel mundial se caracteriza por procesos de deslocalización, es decir que la cadena de valor de un producto atraviesa numerosas instancias en diversas partes del mundo. Esto complejiza identificar la trazabilidad, convirtiéndose en una caja negra en la que no puede reconstruirse con facilidad las etapas y espacios por donde circuló ese producto hasta llegar a las manos del usuario. En este sentido, los consumidores tienen cada vez más poder de decisión y son exigentes con las marcas que consumen (Mon, 2019), por lo que la producción local sustentable emerge como un potencial negocio. "En el mundo global (...), para los países emergentes, el diseño debe formar parte del discurso político del desarrollo (...). Principalmente porque los productos que se integran al intercambio internacional deben ser capaces de comunicar identidad y deben adquirir sentido desde lo local, para tener una oportunidad en el mundo global que busca lo único, lo diferente, lo que puede crear identidad para quien lo usa" (Rodríguez Musso, 2006) ${ }^{14}$. El quid de la cuestión, de las tensiones globales/ locales reside en elaborar herramientas y estrategias, planificadas y sostenibles en el tiempo, que preponderen el reconocimiento del origen como eje central en la generación de valor. Como definen Analía Cervini y Juan Kayser, la importancia de que estos valores vayan mutando en el tiempo, hibridando y sincronizando con el propio contexto y así apoyarse de la construcción colectiva (Cervini y Kayser, 2004).
${ }^{14}$ Extraído de: https://foroalfa. org/articulos/el-diseno-comoestrategia-cultural. Visitado el 9/6/2020. 


\section{A modo de conclusión}

Reflexionar sobre el panorama identitario de la industria textil local, nos lleva a concluir que la misma, atraviesa un proceso de crisis en torno a su identidad. La dificultad reside en la indefinición: fasón o empresa con venta propia, identidad del pasado en un presente totalmente distinto, perfil técnico o perfil comercial, tensión de identidad propia de la marca respecto a las marcas para las que produce, valor artesanal o valor industrial. Esta interpretación nos lleva a definir que no hay una estrategia identitaria clara por parte de las empresas ni del sector. Pero sin embargo, persiste un reconocimiento entre pares y actores del conglomerado que les permite una fuerte presencia "hacia afuera": "No importa tanto "quién es quién" sino "quiénes somos" y, más importante aún "qué hacemos"..." (Miguel, op.cit, p.157). Además, otro dato interesante de resaltar, es la pervivencia en el imaginario colectivo del "pulóver marplatense" en cierto grupo generacional que aún es población activa. Como define Arjun Appadurain, el factor de la imaginación colectiva constituye un combustible esencial para la acción, para la movilización de las personas voluntariamente y que promueve al cambio. En esta misma línea, podemos pensar que estos mundos imaginados, que el autor define como paisajes, están recorridos por actores individuales que a su vez pertenecen a otros macropaisajes y que responden a lógicas globales que los condicionan. Esto nos lleva a pensar en la necesidad de estar a tono con las tendencias mundiales para captar la atención de estos grupos y poder gestionar este imaginario colectivo y hacerlo sobrevivir en el tiempo.

Como varios autores expresan, el valor debe ser gestionado, lidiando en sano equilibrio entre las tensiones producto de lo particular, que podríamos asociar al localismo, y lo universal, producto de sumergirse en la globalidad (Appadurain, op.cit). El sujeto debe generar una conciencia voluntaria cosmopolita (Massey, en Morley, op.cit), que medie entre el saberse local y reconocimiento de sus orígenes, sin perder la mirada de lo global y universal. Siguiendo esta línea, Castells (Castells en Appadurain, op.cit) advierte respecto a los problemas que pueden suscitarse en el desequilibrio de esta delgada línea, que a veces puede diluirse en una relación 
de interactivos e interactuados en términos de identidad. El autor explica que la era posmoderna y sus efectos ha generado una nueva división entre sus actores en términos de participación y posibilidad de accionar consigo mismo y coaccionar sobre otros. Muchas veces la identidad queda relegada a la presión y preponderancia que tienen algunos grupos sobre otros, a partir de la coerción directa o simplemente por la dinámica de seguir al líder.

En este contexto, se reivindica la acción del diseño como constructor de valor intangible y de las pequeñas y medianas empresas como espacio próspero para el embanderar la identidad local. "La producción en pequeña escala es el lugar del nuevo comienzo, de la recuperación del sentido, tiene una posición importante en la construcción de la sustentabilidad y ocupa un sitio de privilegio en los imaginarios de todas las culturas, porque es el lugar del arraigo, del protagonismo, de la unidad espiritual del ser, de la armonía con la naturaleza y de la estética como coherencia vital." (Galán, 2011, p.90). Es este el escenario donde la industria del tejido de punto local debe recuperar, valiéndose de su pasado como prospectiva para reconstruir su identidad difusa. 


\section{REFERENCIAS BIBLIOGRÁFICAS}

Abad, K; Di Clemente, P; Huarte, M. E; Mingo, M; y Prats, S. (1999). Estudio de competitividad del sector textil marplatense: tecnología de organización y administración, tecnología comercial. En Fuster, H; Graña, F y Liseras, N. (Eds.), El sector textil marplatense. Diagnósticos de competitividad y otros estudios (pp. 40-60). Mar del Plata, Argentina.

Allon, F. (2000). Nostalgia unbound. Illegibility and the synthetic excess of place, Continuum, vol. $14, \mathrm{n}^{\circ} 3$, págs. 275-287.

Appadurain, A. (2001). La modernidad desbordada. Dimensiones culturales de la globalización. Ediciones TRILCE, Fondo de Cultura Económica, Buenos Aires.

Boletín Económico de la cadena de valor textil y confecciones. (2017). Informe Fundación Pro Tejer. [En línea]. (2017) Recuperado de: https://www.fundacionprotejer.com/informes/presentacion-de-protextil-2017/

Boletín Económico de la cadena de valor textil y confecciones Abril. (2018). Informe Fundación ProTejer. [En línea]. (2018) Recuperado de: https://protejer.praset.com/archivos/2018/07/Bolet\%C3\%ADnecon\%C3\%B3mico-Abril-2018-1.pdf

Cervini, A.; Kayser, J. (2004). Identidad Estratégica, alternativas locales en mercados globales. IMDI-CMD, Buenos Aires.

Costa, E.; Rodríguez, G. (1998). La industria textil marplatense ante la globalidad y el cambio. FACES N5 (pp. 45-75). Mar del Plata, Argentina.

Favero, B. (2014). La última inmigración. Italianos en Mar del Plata (1945 - 1960). Imago Mundi. Buenos Aires, Argentina.

Favero, B. (2014). Domestic Textile Work among Italian immigrant Women in Post-World War II Mar del Plata, Argentina. En Giunta E. y Sciorra J. (Eds.), Embroidered Stories: Interpreting Women's Domestic Needlework from the Italian Diaspora, Jackson, (pp. 193-206), University Press of Mississippi, Estados Unidos.

Favero, B. (2012). L'esperienza immigratoria Italiana del dopoguerra nella città di Mar del Plata, 1947-1960. Credito Trevigiano. Treviso, Italia. 
Favero, B. (2011). Las tramas de una identidad: el trabajo textil doméstico entre las mujeres inmigrantes italianas de posguerra en Mar del Plata a partir de entrevistas orales. Jornadas Internacionales Sociedad, Estado y Universidad. Mar del Plata, Argentina.

Galán, B. (2011). Diseño, proyecto y desarrollo. Miradas del período 2007-2010 en Argentina y Latinoamérica. Wolkowicz Editores, Buenos Aires.

Gennero de Rearte, A. y otros (2008) Conductas innovativas de las firmas en aglomeraciones productivas del sector textil-confecciones. XIII Reunión Anual de la Red Pymes Mercosur. Universidad Nacional de General San Martín, Argentina.

Miguel, P. (2013). Emprendedores del Diseño: Aportes para una sociología de la moda. Eudeba, Buenos Aires.

Mon, L. (2019). Informe Marcas en Tiempos de furia. Observatorio de Tendencias INTI, Argentina.

Monacchi, M.C.; Canetti, R. (2018). Teorizando el mapa del diseño. Caso CeDiS, Mar del Plata, Argentina. Revista DAYA, Ecuador.

Monacchi, M.C (2020). Diagnóstico de la cadena de valor textil marplatense a partir de la herramienta analítica del Design Thinking. Informe final de beca tipo A, Universidad Nacional de Mar del Plata. Aún no publicado.

Monacchi, M.C. (2017). Destejiendo historias y recuperando la identidad del tejido de punto marplatense. Revista Investigación + Acción, 20(19), 61-78.

Monacchi, M.C. (2015). Tejido de punto marplatense: de la tradición inmigrante a la consolidación como polo productivo sustentable regional. Informe final de Beca UNMdP.

Morley, D. (2001). Belongings. Place, space and identity in a mediated world. European Journal of Cultural Studies, ${ }^{\circ} 4(4)$, Londres Sage Publications.

Rech, L. (2019). Exposición Estudio global de las empresas del sector textil y confecciones Mar del Plata-Batán. Grupo de Análisis Industrial. Centro de Investigaciones Económicas y Sociales, FCEyS, UNMdP. Torreón del Monje, Mar del Plata, Argentina.

Rodríguez Musso, A. (2006). El diseño como estrategia cultural, Foroalfa, Investigadores de Arte, Buenos Aires. [En línea]. Recuperado de: https://foroalfa.org/articulos/el-diseno-como-estrategia-cultural

Ruppel C. (2017). Tercerización Textil, la Otredad de la Producción. Caso Mar del Plata. Cuarto Congreso DiSUR Dimensión política del diseño en Latinoamérica. Debates y desafíos, Mendoza. 